\section{Textos
Informativo}

Edilene Coffaci de Lima

(UFPR)

\title{
Um festival e seu reverso, etnografia involuntária'
}

Fui convidada a participar do VI Festival dos Povos Katukina da Terra Indígena Katukina, localizada em Cruzeiro do Sul (AC), em fevereiro de 2014, por intermédio de Shere (Benjamim André) morador da aldeia Samaúma, onde o evento deveria ocorrer. Entusiasmada com a ideia de reencontrar os Katukina após dois anos e meio de ausência, aceitei prontamente o convite e passei a me organizar para que pudesse cumpri-lo. Na extensa programação do evento estavam incluídos, entre outras coisas, diversos jogos ou "brincadeiras" que conhecia desde os primeiros anos de minhas pesquisas entre eles, que se iniciaram em 1991. O Festival ocuparia três dias, de 17 a 19 de abril, com um conjunto de atividades tidas como "culturais" e ou "tradicionais", como as brincadeiras da cana, do mamão e da lama.

Cheguei a Cruzeiro do Sul no dia 16 de abril, no começo da tarde. No mesmo dia dirigi-me à FUNAI para me apresentar aos funcionários que estavam apoiando os Katukina na realização do evento. Naquela ocasião conversei mais longamente com Jairo Lima, vice-coordenador da Regional do Vale do Juruá, que me falou das últimas reunióes havidas para que o Festival pudesse transcorrer a contento, sem sobressaltos. Disse-me então que havia sido combinado de se fazer uma listagem de todos os visitantes da Terra Indígena que participariam do festival. O acordo havia envolvido não apenas os próprios Katukina e a FUNAI, mas também agentes do Instituto Brasileiro de Meio Ambiente (IBAMA) e da Polícia Federal (PF). Não me furtei a lhe transmitir meus dados pessoais, entre os quais se incluíam, menciono de memória, além de meu nome, o número do documento de identificação, a profissão, o local de trabalho, as datas de chegada e partida e o meio de transporte utilizado. Acabei encabeçando a lista, sendo a primeira a constar em seu preenchimento - desconheço o uso que foi feito da mesma. Ainda na FUNAI conheci outros servidores como Luiz Nukini (coordenador da Regional do Juruá, na verdade já meu conhecido, pois visitei a aldeia em que morava seu pai em 1991, quando ele ainda era uma criança), Ariel Renê, João Santos e Marco lunsten. 
No dia 17 teria início o festival e desloquei-me para a TI com o apoio da FUNAl, em um de seus carros. O Festival acabou me parecendo menos frequentado do que tinha imaginado encontrar, restando evidente notar que não estavam presentes os parceiros de alguns dos Katukina mais jovens envolvidos nos últimos anos com a difusão urbana do kampô ou kambô, a secreção da perereca Phyllomedusa bicolor. Em resumo, não havia ali qualquer um dos terapeutas esotéricos de que já tinha ouvido falar e sobre os quais já havia escrito alguns artigos (ver Lima; Labate 2007 e 2008). No evento criado no Facebook constavam aproximadamente 400 convidados externos. Os que lá estiveram efetivamente não somavam um décimo disso, não ultrapassando mais que 15 pessoas, aí incluídas algumas de etnias vizinhas, como Marubo e Kaxinawá.

A expectativa de número tão avantajado de pessoas presentes, é inevitável dizer, era de apenas alguns dos organizadores e a ausência de tais convidados não retirou da festividade sua alegria e empolgação - empolgação, aliás, pela qual os Katukina são bastante conhecidos. A grande parte dos Katukina não expressou qualquer pesar pela falta dos convidados e entregaram-se às brincadeiras com uma vitalidade que faz valer o que se diz regionalmente acerca deles, principalmente a respeito das mulheres, que não poupam os homens para obter a vitória nos jogos. Como é sabido, são alvos preferenciais de tais brincadeiras, sobretudo, os visitantes e não foi com surpresa que pude presenciar os agentes da Polícia Federal e do lbama - presentes, segundo consta, para garantir a fiscalização da festa, quando os organizadores ainda aguardavam um grande número de participantes externos - entrarem em suas picapes e saírem em disparada quando as mulheres correram em sua direção. Não havia ali nenhuma prévia restrição aos agentes. É sempre assim, com todos os visitantes, independentemente de quaisquer credenciais. Lembro-me ainda como, na década de 1990, antes da pavimentação da rodovia, as mulheres corriam e enlameavam qualquer branco que, a caminho para Cruzeiro do Sul, inadvertidamente passasse pelo lugar enquanto uma brincadeira estivesse sendo realizada. Uma viagem a pé, já bastante dura, poderia ficar pior.

Logo no primeiro dia, na "cerimônia de abertura", compareceu o vice-governador, César Messias, e, após sua partida, tiveram início as brincadeiras (fragmentos de antigos rituais) que realmente interessavam. Como é de costume, envolvi-me nas diversas brincadeiras, minhas conhecidas de outras épocas e que tinham, inclusive, sido incluídas na etnografia que apresentei em meu mestrado, desenvolvido na Universidade de São Paulo. Foram três dias praticamente ininterruptos da realização das brincadeiras propriamente ditas. É inevitável reconhecer que as duas décadas que frequento a terra indígena e conheço aquelas pessoas facilitavam a identificação das transformações. Não é esse o lugar para elencar e pontuar todas, mas duas, de tão salientes, cabe mencionar. A primeira delas é que faltava mamão para dar curso à "brincadeira de mamão", quando as mulheres devem arrancá-lo das mãos dos homens, sempre às custas de muitos tapas, empurrões e puxões de cabelo, restando aos homens apenas ofendê-las verbalmente. Não que o mamão não tenha feito falta, mas foi com facilidade substituído por cocos-verdes comprados nas cercanias da terra indígena, de pequenos agricultores dos projetos de colonização que a cercam. Como se rompe menos facilmente que os mamões-verdes, as brincadeiras com os cocos acabavam também durando mais e criavam novas técnicas de "dribles" das mulheres, com os cocos rolando pelo chão... Uma segunda mudança é talvez mais saliente: aconteceu uma "mesa de rapé". Ou seja, homens posicionados do lado de 
três mesas escolares alinhadas assopravam rapé nas narinas de rapazes e moças que eram conduzidas em tom de desafio até a mesa, ficando diante dos "assopradores". Os homens prestavam-se mais voluntariamente a receber os sopros de rapé. Os brancos responsáveis pela fiscalização da festa não se furtaram desta vez a participar da atividade proposta. Nesta sessão possivelmente tenha ocorrido o momento mais tenso de todo o festival: uma moça relutante a receber o rapé foi constrangida pelos rapazes a recebê-lo, gerando gritos de insatisfação de seu pai que se posicionava relativamente perto, mas adoentado o suficiente para não ir até a mesa interromper a sessão. Jamais vira ou tivera conhecimento nos anos anteriores de campo que realizei por toda a década de 1990 de tais "mesas de rapé", menos ainda de que as mulheres fizessem uso dele. Seguramente a novidade articula-se com a difusão do kampô que teve início a partir do início deste século. Junto com o kampô, o rapé passou a difundir-se como um produto "autenticamente indígena".

Um diálogo que tive com um velho conhecido dá aproximadamente o tom das mudanças em curso. Logo pela manhã, enquanto todos ainda se ajeitavam para mais uma jornada de brincadeiras, esse homem chegou todo arrumado, de calça branca, chinelo e sem camisa, trazendo nas costas um casco de jaboti, todo oco certamente, pendurado ao modo de um pingente. Indaguei-o: "Que enfeite é esse? Jamais vi isso por aqui!". Ele não teve dúvidas ao me responder: "Cultura nova". Rimos, certamente por diferentes motivos, de sua saborosa resposta. A concepção de cultura em vigor localmente, que tudo pode abranger, inclui as inovações, quaisquer novos objetos ${ }^{2}$ - não apenas o que se pode querer conceber apressadamente como "tradicional".

As mudanças que pude presenciar não cessavam, contudo. Uma delas é que todas as pessoas reunidas nas imediações da aldeia Samaúma, onde foram construídos pequenos tapiris para hospedar os presentes ao Festival, alimentavam-se durante aqueles dias exclusivamente do patrocínio estatal. Apoios obtidos via governo estadual (especialmente a partir do Departamento de Estradas e Rodagens do Acre - DERACRE) é que garantiam que ali haveria alimentos e água para todos. Logo no primeiro dia chegou um carregamento com café, refrigerantes, biscoitos, arroz, carne de boi e peixes. Foi também abastecida de água uma grande caixa d'água para que as pessoas pudessem saciar a sede. A TI do rio Campinas é muito mal abastecida de água, sendo cortada apenas por pequenos igarapés, e aquele apoio acabava sendo fundamental para garantir a reunião de tantas pessoas em um único local. Antes do último dia o problema já se anunciava: faltava água e as pessoas não tinham mais como garantir uma boa alimentação.

O Festival encerrou-se de uma forma meio anticlimática, no Dia do Índio, em virtude de uma forte chuva que caiu na tarde do dia 19 de abril e que impediu a realização do encerramento formal. Cada família retornou, sem cerimônia, para sua própria casa. No mesmo dia fui embora também para a cidade, dado que meu voo de volta para Curitiba teria início no começo da tarde do dia 20.

Antes de encerrar minhas impressões sobre o Festival, é preciso mencionar que durante os três dias pude ainda fazer pequenos passeios pela Terra Indígena e conhecer as casas que foram construídas em 2013, a partir do Programa Minha Casa, Minha Vida, do governo federal. No Acre as referidas casas foram construídas nas Tls do rio Campinas e dos Kaxinawá da Colônia 27, as duas mais impactadas pela pavimentação da rodovia BR-364 no 
início deste século. A planta das casas tem uma sala, dois quartos, cozinha e banheiro, construídas parcialmente em madeira e alvenaria e coberta com telhas. Infelizmente não houve tempo para que pudesse conhecer a dinâmica cotidiana das casas com seus moradores, e os possíveis usos e ajustes que devem estar fazendo para comportar outro arranjo familiar e cultural que o imaginado pelos agentes públicos. Ao total foram construídas na TI do rio Campinas pouco mais de 120 novas casas, supostamente "respeitando as tradições dos povos indígenas", segundo divulgado virtualmente pelo governo do estado ${ }^{3}$.

Foi numa dessas visitas que pude ter notícias também sobre a passagem da Linha de Transmissão de Energia Elétrica - o Linhão - de Rio Branco para Cruzeiro do Sul (ainda hoje abastecida de energia por uma usina a diesel), que deve atravessar toda a TI do rio Campinas, seguindo o curso da BR-364. Algumas pessoas comentaram que havia dúvidas sobre se permitiriam a passagem da linha seguindo a estrada ou se demandariam que contornasse a TI. Uma das lideranças locais refletia que fazer o Linhão contornar a fronteira da TI poderia aumentar ainda mais o impacto sobre o estoque faunístico, dado que seria preciso desmatar alguns quilômetros de áreas para a instalação das torres. Até onde sei, a definição do assunto não está consolidada, e desconheço se existe em andamento estudo para mensurar impactos do tipo mencionado. Era pouco tempo, em meio a um intervalo da festa, para alcançar informações mais detalhadas sobre o assunto.

A pavimentação da rodovia, no início deste século e a perspectiva futura de passagem do Linhão compõem o pano de fundo do que tenho acompanhado na última década e meia, com repercussões fortes para os Katukina, para não dizer das demais populações indígenas do alto Juruá. Assim, não bastassem os impactos da pavimentação da rodovia e a construção vindoura do Linhão, não se deve perder de vista de que no alto Juruá, nos próximos anos, os maiores impactos previstos vêm da prometida exploração de petróleo e gás na região. Os impactos, de alguma maneira, já tiveram início com a prospecção que, como era esperado, identificou petróleo e gás nas imediações de terras indígenas. Em 2013, um técnico da ANP disse em entrevista ao jornal A Tribuna, de Rio Branco, que o "Acre está rodeado de gás e petróleo por toda parte" (Aquino 2013). A Agência Nacional de Petróleo (ANP), atendendo à legislação ambiental insistentemente lembrada pelo movimento indígena, não prospectou nas Terras Indígenas, mas em suas imediações - a dez quilômetros de distância de suas fronteiras. O resultado confirmou o que era esperado e se planeja dar início à exploração, ao que parece, sem se mensurar adequadamente os impactos que daí podem advir, sem também que sejam devidamente ouvidas as populações afetadas, conforme matéria publicada pelo Conselho Indigenista Missionário (CIMI 2014).

Abrindo um longo parêntese e desviando-me bastante do Festival Katukina de 2014, resta destacar que a potencial exploração petrolífera no alto Juruá acaba tornando pequenos os impactos que já se conhecem da pavimentação da rodovia. Até agora, entretanto, não existem quaisquer ações para remediar ambas situações, o que faz a cumulatividade de ambos processos ainda mais pronunciados. Sobre a exploração petrolífera restam sem resposta várias perguntas. Em 2007, publiquei, em co-autoria com Mauro Almeida e Marcelo Piedrafita, um artigo na coluna "Papo de Indio", mantida por Terri de Aquino em um periódico de Rio Branco, o Página 20. Naquela ocasião já perguntávamos, por exemplo, sobre como se planeja escoar a produção de petróleo e gás: 
Planeja-se escoar essa produção pelo Juruá e por água até Manaus, pelas estradas ou por meio da construção de um oleoduto? (...) Será pela BR-364, de Cruzeiro do Sul até Rio Branco, para seguir para o restante do Brasil e, pela BR-317, para o Peru, pela Rodovia Transoceânica? Haveria uma terceira alternativa, ainda não comentada: realizar outra integração rodoviária com o Peru, estendendo a BR-364, cortando florestas dos rios Juruá e Ucayali, aí incluído o PNSD, até Pucallpa, capital do Departamento do Ucayali. Ou seja, por uma segunda estrada binacional até o Pacífico. Se for por um oleoduto/gasoduto, quais seriam os traçados possíveis? Para Coari, rasgando imenso trecho de florestas no alto e médio cursos do rio Juruá? Para oeste, para o Peru? (Lima; Almeida; Piedrafita 2007)

Para todas as perguntas, formuladas originalmente já há algum tempo, não se esboçaram até o momento quaisquer respostas, oferece-se apenas a velha promessa de desenvolvimento e progresso emergentes.

Voltando à viagem de 2014, de volta à cidade, já no dia 20 de abril, aproximadamente às 13 horas, dirigi-me ao aeroporto de Cruzeiro do Sul, para começar meu retorno a Curitiba. Cheguei ao aeroporto por volta das 13h20 e dirigi-me ao check-in da companhia aérea. Sem que se tenha passado meio minuto, ouvi o sistema de som do aeroporto me chamando para apresentar-me aos operadores da companhia aérea. Retornei ao check-in e me apresentei, disse que era a pessoa que tinha o nome anunciado no sistema de som. Fui orientada a entrar na sala de embarque e buscar informações por lá. Na fila do embarque ouvi uma segunda chamada de meu nome no aeroporto e a mesma recomendação. Saí da fila, procurei uma operadora da companhia aérea e ela me aconselhou a entrar na sala de embarque. Voltei para a fila e ouvi uma terceira chamada. Esperei a fila andar e ao entrar na sala de embarque identifiquei-me então pela terceira vez com um operador da empresa aérea. Em resumo, mais uma vez apresentei-me como a pessoa tão insistentemente chamada no sistema de som do aeroporto. Foi então que apareceu um agente da Polícia Federal, que perguntou se minha bagagem de mão havia passado pelo raio X. Evidentemente respondi que sim, afinal, é esse o procedimento padrão para todos as bagagens. Ele perguntou então do restante de minha bagagem e respondi que havia sido despachada. Sem maiores explicações e sem que pudesse entendê-lo, ele retirou-se. Como a fila do embarque encerrava-se e sem que tivesse explicações, embarquei também.

Já dentro da aeronave, mais uma vez fui chamada pelo sistema de som. Identifiquei-me com uma comissária de bordo e fui orientada a retirar-me da aeronave. Fui então conduzida ao local onde estavam as bagagens, sendo recebida com hostilidade por um agente da Polícia Federal, que dizia que havia me recusado a colaborar com o procedimento de fiscalização, pois não me havia apresentado quando chamada. Um equívoco, pois havia me apresentado para os funcionários da companhia aérea todas as vezes em que fui chamada, sem que recebesse as instruções adequadas. Estávamos diante do carrinho que transporta as bagagens até a aeronave e foi retirada a lona que as encobria, pois chovia moderadamente. Logo acima de todas as bagagens, estava a minha. Identifiquei-a e ela foi retirada. $\mathrm{O}$ agente da $\mathrm{PF}$, um tanto quanto exaltado, ordenou que a abrisse. Abri a parte principal e recebi uma outra ordem: "retire as coisas daí". Comecei a retirar, mas paralisei-me diante da humilhação que estava 
passando com ordens consecutivas, como se pudesse ser tratada de tal maneira, com tamanha arbitrariedade. Parei de retirar as roupas e respondi com alguma impaciência: "o trabalho aqui é seu, ficarei aqui olhando, faça o seu próprio serviço, pode revirar minha bagagem que não encontrará nada a não ser a rede, a coberta e roupas sujas". O agente impacientou-se um tanto mais e revirou, com a ajuda de um segundo agente, a minha bagagem, sem, evidentemente, nada encontrar. Foi então que disse a ambos - tendo neste ambiente também dois ou três agentes do IBAMA que acompanhavam a operação de investigação e que havia conhecido nas festividades na TI Katukina do rio Campinas - algo como "vocês pegaram a pessoa errada". Se supostamente aquela operação realizada no aeroporto de Cruzeiro do Sul objetivava apreender paletas de kampô ou quaisquer outras coisas traficadas a partir da TI do rio Campinas (ou seja, se pesavam contra mim suspeitas de biopirataria), eles haviam se equivocado, pois sou uma pessoa que os respeita imensamente e com as quais nutro relações de amizade há bastante tempo, já se vão mais de duas décadas. Insisti que se eles procuravam por paletas de kampô, deveriam investigar melhor, pois se percebia muito rapidamente que não estavam conseguindo distinguir uma pesquisadora de boa-fé, que tem uma longa história de apoio e parceria com os Katukina, de quaisquer oportunistas que pudessem estar procurando. Intimamente imaginava que pudessem ter me confundido com alguma entusiasta do uso de práticas esotéricas, da ayahuasca e do kampô, dados os desenhos geométricos que uma mulher katukina, usando jenipapo, havia feito em meus dois braços e que estavam ainda bastante visíveis... Falei de minha longa experiência entre os Katukina e de minhas atuais pesquisas, que têm como tema justamente a difusão do kampô em ambientes urbanos e também como foco de disputas - portanto, bastante transformado em relação ao que conhecera nos meus períodos de campo na década de 1990. Sem querer aborrecê-lo, mencionei que não era muito difícil tratar da apropriação indevida do kampô, que informações sobre isso existem em abundância na internet, não seria muito difícil eles próprios investigarem melhor. Em resumo: insisti que erraram o alvo. O mais exaltado dos agentes da operação da PF - sugestivamente intitulada de Ibugaína ${ }^{4}$ irritou-se bastante com minha fala e acusou-me de querer ensiná-lo como fazer o seu trabalho. Evidentemente não foi essa a intenção nem pretendia ofendê-lo, mas chamar a atenção para a miopia institucionalizada e para a desproporção do tratamento que me foi oferecido - intimidatório, truculento e desrespeitoso, para dizer o mínimo.

A essa altura minha bagagem já estava novamente fechada e imaginei que pudesse me retirar e retornar à aeronave para seguir viagem, dado que evidentemente nada tinham encontrado. $\mathrm{O}$ tal agente da $\mathrm{PF}$, inconformado com o que ele entendeu como sendo minha insubordinação (por não ter me apresentado rapidamente, desde que chamada pela primeira vez, e por questionar o tratamento que me foi dispensado, tendo-me imediatamente como "suspeita" sem que pudesse prestar quaisquer explicações - aliás, nenhuma pergunta foi-me feita) continuou com seu exercício de autoridade e deu-me voz de prisão por "desacato à autoridade", conduzindo-me à delegacia da PF "para averiguação". Uma comissária de bordo retirou minha bagagem de mão da aeronave e fui conduzida pelos dois agentes da PF em uma viatura própria, não soube para onde se dirigiram os agentes do IBAMA.

Antes de entrar no carro insisti que o tratamento que me foi dispensado estava completamente desproporcional, que nada pesava contra mim e foi então que ouvi do agente de sempre: “O que você pensa? Você me desautoriza 
na frente do pessoal do IBAMA, fui obrigado a lhe prender". A responsabilização da vítima entrou então em cena. Daí em diante, calei-me, era prudente não me expor mais diante de tamanho despreparo e arbitrariedade.

$\mathrm{Na}$ delegacia da PF não cessaram as surpresas, e a pior ainda estaria por acontecer. Sentei-me no lugar que me fora indicado, logo na entrada, enquanto os policiais se retiraram. Pelo que pude ouvir à distância, parece-me que telefonaram para chamar o delegado, afinal, era feriado de Páscoa e ele não se encontrava. Na volta dos policiais, me chamaram para acompanhá-los. Levantei-me e tentei pegar minha bolsa, pois imaginava ser conduzida para alguma sala até a chegada do delegado. Ouvi então: "deixe suas coisas aí!". Obedeci e segui-os pelos caminhos que me indicavam e eis que me dei conta do quanto a arbitrariedade não tem limites: estava diante de um corredor de celas, todas vazias, e na primeira fui encarcerada, sem direito a qualquer palavra, pergunta, questionamento ou esclarecimento. Já encarcerada, um segundo policial, o mesmo que havia me abordado quando fui chamada pela terceira vez no sistema de som do aeroporto e por três vezes consecutivas me apresentei, perguntou se gostaria de tomar água. Disse que sim, ele retirou-se e voltou com um copo de plástico que me passou pela grade. Daí em diante, apenas ruídos estranhos no corredor lateral, agitação e alguns períodos de absoluto silêncio. Não sei realmente descrever a intensidade das emoções que vivi, das viagens da minha imaginação olhando para todos os cantos da cela. Claro que tinha consciência de que nada de pior aconteceria, já tinha chegado ao limite, mas a imaginação é livre, voluntariosa e ficou vasculhando cada centímetro daquele lugar feio, tentando juntar peças que explicassem o absurdo da situação.

Por aproximadamente duas horas fiquei detida, até que fui desencarcerada e encaminhada à presença do delegado e do escrivão. Aliviada, respondi aos questionamentos que me foram, finalmente, feitos. Tratada um tanto mais respeitosamente, expliquei ao delegado os objetivos de minhas pesquisas e de como o kampô me interessa mais pelos efeitos que gera sociologicamente que pelos que pode gerar física ou comercialmente. Aliás, esqueci de dizer ao delegado, por exemplo, que nunca sequer experimentei o kampô - nem no festival nem nos períodos anteriores de trabalho de campo entre os Katukina ${ }^{5}$. Em resumo, a "suspeita" conhece o kampô sociológico apenas, o que se diz e o que se faz com sua difusão fora das aldeias e sua consequente transformação - mas não conhece a transformação que pode produzir nos corpos. Bom, mas isso nem seria necessário dizer, não convinha e talvez ele nem estivesse mesmo interessado em saber.

Após assinar os papéis acabei sendo liberada, mas não completamente, pois faltava ainda o exame de corpo delito. O mesmo policial que me deu voz de prisão e que me encarcerou, conduziu-me até o Hospital do Juruá, onde um médico plantonista estava orientado para fazer o exame. Dentro do consultório o policial parecia não poder se conter e perguntou ao médico, possivelmente querendo me intimidar: "devemos nos retirar para que o senhor possa realizar o exame, não?". Ouço então uma voz mais equilibrada, a do médico, que responde: "não, podem ficar aí, é simples". O médico dirigiu-se então a mim e perguntou sem ambiguidade: "tem alguma lesão derivada dos últimos acontecimentos?". Respondi prontamente: "não". Ele rapidamente preencheu o formulário, imprimiu seu carimbo sob sua assinatura e fui então totalmente liberada. Talvez eu não fosse a única pessoa aliviada ali. Uma amiga, Dedê Maia, Assessora de Assuntos Culturais Indígenas da Fundação Elias Mansur (FEM-AC), que havia 
também participado do Festival Katukina, e Jairo Lima, vice-coordenador da FUNAI em Cruzeiro do Sul, o mesmo a quem tinha disponibilizado todas as minhas informações logo que cheguei à cidade, aguardavam-me para me conduzir ao hotel, não tinha mais que ser guiada pela PF.

O episódio parece encerrar-se na minha liberação da "averiguação", mas não. Estou segura de que o que ocorreu não foi uma "operação de rotina", como, após ser liberada, tentou me convencer o delegado. Se não, por que foram tão determinados na procura, chamando por mim consecutivamente no sistema do som do aeroporto e depois, de alguma maneira, me expondo a constrangimentos públicos, como minha retirada de dentro do avião? Meu check-in mal acabava de ser concluído e meu nome já podia ser ouvido por toda parte. Como sabiam que estava ali para embarcar, como chegaram a mim e que me fizeram "suspeita"? O que houve foi sim uma ação arbitrária e equivocada, com o exercício da autoridade e da repressão desproporcional ao fim que se desejava alcançar.

No dia seguinte, 21 de abril, reiniciei minha viagem de volta, tendo pago pela remarcação (em um feriado) vultosas taxas à companhia aérea. Para deslocar-me até o aeroporto, ainda em Cruzeiro do Sul, pedi para que me acompanhassem, e se certificassem de minha efetiva partida, os amigos Dedê Maia e Luiz Nukini. Desta vez não estavam presentes no aeroporto os agentes da PF em suas "ações de rotina", apenas os agentes do IBAMA, que havia conhecido durante o Festival, visivelmente constrangidos de me reencontrarem no mesmo local do dia anterior - troquei amenas palavras com um deles.

Deve haver alguma coisa a ser retida de tal episódio. Uma delas é que, infelizmente, fica claro que enquanto agentes públicos se concentrarem apenas em perseguir e criminalizar aqueles que sem muitas explicações têm como "suspeitos", muito pouco poderão estar fazendo ou contribuindo para garantir o respeito aos conhecimentos e práticas tradicionais ou para impedir sua apropriação indevida por pessoas de todas as partes. A síndrome persecutória - ou a bioparanoia, neste caso - gerou um grande equívoco, mas não se pode resumi-lo e entendê-lo como se fosse um mal-entendido. Sim, é inevitável insistir que miraram no alvo errado e pegaram a pessoa errada. Quais interesses orientam tal conduta restam, ainda, como uma incógnita. Ironicamente, o projeto de pesquisa em que participava então (concluído em outubro de 2014) tinha como foco de interesse justamente os efeitos gerados pelos direitos intelectuais e culturais sobre os conhecimentos tradicionais. Experimentei involuntariamente alguns desses efeitos.

Para encerrar, não deve ser demais lembrar que sou também um agente público, professora de uma universidade pública federal (a UFPR) e estava no exercício de minhas funções, autorizada pelo meu departamento a afastar-me de minha instituição para participar do festival, que afetava diretamente o meu tema de pesquisa. Quase doze meses já se passaram, mas ainda muito me constrange pensar que estou sendo imputada por ter supostamente ofendido a União, conforme consta do Termo Circunstanciado registrado na ocasião.

Passados alguns meses do fatídico episódio resta o reconhecimento excessivamente próximo de que a função pública tão importante como a que exercem os policiais federais deveria ser encarada com maior serenidade e responsabilidade. No mais, não há quaisquer dúvidas de que as aceleradas transformações que estão em curso nos dias de hoje no alto Juruá, e que afetam muito proximamente os Katukina e demais populações indígenas e 
tradicionais da região, asseguram que deve haver sim fiscalização do tráfico de quaisquer objetos e substâncias, mas também dos diversos usos e explorações que se vêm fazendo da floresta. Contudo, caso ocorram efetivamente tais fiscalizações, que sejam bem planejadas e realizadas, para evitar o confronto e a suspeição entre aqueles que, se não necessariamente aliados, não teriam porque se colocarem como antagonistas.

Por fim, registro aqui meus agradecimentos àqueles que me auxiliaram e se solidarizaram comigo em Cruzeiro do Sul. No momento em que tudo aconteceu, agradeço especialmente à amiga Dedê Maia; através dela aos demais. Institucionalmente agradeço aos colegas da UFPR, da ABA e da ANPOCS pelas moções de apoio e pela divulgação dos fatos. Em Curitiba, quando, em julho de 2015, fui chamada à Justiça Federal para o estabelecimento de uma transação penal, agradeço especialmente ao meu sindicato (a APUFPR-SSIND) por ter se incumbido do pagamento dos honorários do advogado que me assistiu no processo e na audiência. Em tempo: a ABA encaminhou um pedido de esclarecimento do ocorrido ao Ministério da Justiça (MJ) que, na sequência, solicitou esclarecimentos ao Delegado da PF de Cruzeiro do Sul. Tendo recebido a resposta do referido delegado, o Ouvidor Setorial do Departamento de Polícia Federal em Brasília, em 15 de maio de 2014, respondeu à diretoria da ABA afirmando que "todo fato contèm (sic) duas versões". Por sua vez, o Conselho Universitário (COUN) da UFPR aprovou por unanimidade uma moção de apoio e encaminhou, em julho de 2014, uma solicitação “de esclarecimentos e providências" ao MJ. Transcorridos dez meses, recebeu a resposta do Ministério da Justiça informando que, na Delegacia da Polícia Federal de Cruzeiro do Sul, "foi instaurada Comissão de Sindicância" para a apuração dos fatos, sendo que os trabalhos ainda não teriam sido concluídos. (maio/2015) 


\section{NOTAS}

1 Esta nota informativa é uma ampliação da nota publicada no portal da Associação Brasileira de Antropologia (ABA) sob o título $O$ dia em que fui presa pela PF de Cruzeiro do Sul, etnografia involuntária, cf http://www.portal.abant.org.br/images/Noticias/Etnografia involunt\%C3\%A1ria_abr2014_v3.pdf.

2 Assim, sem que seja o caso de desenvolver extensamente aqui, cabe indicar que a palavra "cultura" foi recentemente traduzida pelos Katukina como noke haweti ("nossas coisas"), e tal definição abrange tudo quanto possa existir, de natureza material ou imaterial, sejam cestos, colares e cantos, sejam como espingardas, canetas e gravadores. Tratei um pouco mais de tal tradução em Lima 2012. Seguramente o pingente de jaboti de meu interlocutor cabe em tal definição, marcada por ser bastante inclusiva, comportando os processos criativos

3 Conforme consta em Governo entrega mais de 165 moradias para indígenas do Juruá, recuperado em 28 janeiro, 2015, de http://www. agencia.ac.gov.br/noticias/acre/governador-entrega-mais-de-165-moradias-para-indigenas-jurua.

4 É inevitável observar que há registros na internet do uso conjugado de kampô (ou kambô) e iboga (Tabernanthe iboga) na Europa, justamente a planta que inspirou os nominadores da operação no aeroporto de Cruzeiro do Sul. Sobre a conjugação do uso das duas substâncias, ver uma matéria, postada em um site tcheco, com o seguinte título: Kambô e iboga como sinergia. Como essas medicinas sagradas trabalham juntas. Cf. Recuperado em 16 novembro, 2013, de http://www.plantsandfrog.org/kamboga_by_giovanni_en.html.

5 Nos meus períodos de campo mais prolongados, na década de 1990, o kampô jamais me fora oferecido, certamente porque seu oferecimento poderia ser ofensivo, pois era recomendado, sobretudo (de uma perspectiva feminina) para as preguiçosas. Desde o início da difusão urbana de seu uso, a partir do início deste século, retornei a campo e foi-me feita a oferta de "experimentar" o kampô, mas àquela altura preferia me manter a distância, e produzir uma diferenciação em relação àqueles que o buscavam por motivos esotéricos, não necessariamente nativos. Conhecendo o uso nativo, preferia me esquivar dizendo que não me reconhecia nem era reconhecida como "preguiçosa" (tikishya). 


\section{REFERÊNCIAS BIBLIOGRÁFICAS}

AQUINO, Romerito. 2013. Acre está rodeado de gás e petróleo por todos os lados. Recuperado em 11 outubro, 2013, de http://www.jornalatribuna.com.br/Mostrar.jsp?id=39386.

CIMI. 2014. Povos indígenas reunidos em Cruzeiro do Sul dizem não à exploração de petróleo no Juruá. Recuperado em 30 janeiro, 2015, de http://www.cimi.org.br/site/pt-br/?system=news\&action=readfid=7501.

IUNSTEN, Marco A. 2014. Ë shovo, Minha Vida: entrega de casas populares na Terra Indígena Campinas/Katukina. Recuperado em 28 janeiro, 2015, de http://crjurua.blogspot.com.br/2014/02/e-shovo-minha-vida-entrega-de-casas. html.

LIMA, Edilene. 2005. "Kampu, kampô, kambô. O uso do sapo-verde entre os Katukina". Revista do Serviço do Patrimônio Histórico e Artístico Nacional 32: 254-267.

2008. "As novas formas do kampô: elementos de uma sociologia da disseminação urbana dos saberes nativos". In: M. Lenaerts; A. M. Spadafora. (orgs.). Pueblos indígenas, plantas y mercados. Amazonía y Gran Chaco. Bucharest: Zeta Books.

2009. “Entre o mercado esotérico e os direitos de propriedade intelectual: o caso do kampô (Phyllomedusa bicolor)". In: S. Kishi; J. Kleba. (orgs.). Dilemas do acesso à biodiversidade e aos conhecimentos tradicionais. Direito, política e sociedade. 1ed. Belo Horizonte: Fórum.

2012. "A gente é que sabe ou sobre as coisas katukina (pano)" Revista de Antropologia 55 (1): 139-169.

(no prelo). "A internacionalização do kampô (via ayahuasca): difusão global e efeitos locais". In: M. Carneiro da Cunha; P. Cesarino. (orgs.). Políticas culturais e povos indígenas. São Paulo: Edunesp.

; ALMEIDA, Mauro; PIEDRAFITA, Marcelo. 2007. Petróleo, gás, estradas e populações tradicionais. Recuperado em 02 agosto, 2007, de http://uc.socioambiental.org/noticia/petroleo-gas-estradas-e-populacoes-tradicionais-noalto-jurua.

; LABATE, Beatriz C. 2007. "Remédio da Ciência e Remédio da Alma: os usos da secreção do kambô (Phyllomedusa bicolor) nas cidades". Campos 8: 71-90.

; 2008. "A expansão urbana do kampô: notas etnográficas". In: B. C. Labate; S. L. Goulart; M. Fiore; E. MacRae; H. S. Carneiro. (orgs.). Drogas e cultura: novas perspectivas. Salvador: EDUFBA.

LIMA, Jairo. 2013. Conversando sobre o linhão. Recuperado em 29 janeiro, 2015, de http://crjurua.blogspot.com. br/2013/07/conversando-sobre-o-linhao.html.

Recebido em 29/01/2015

Aprovado em 03/02/2015 